
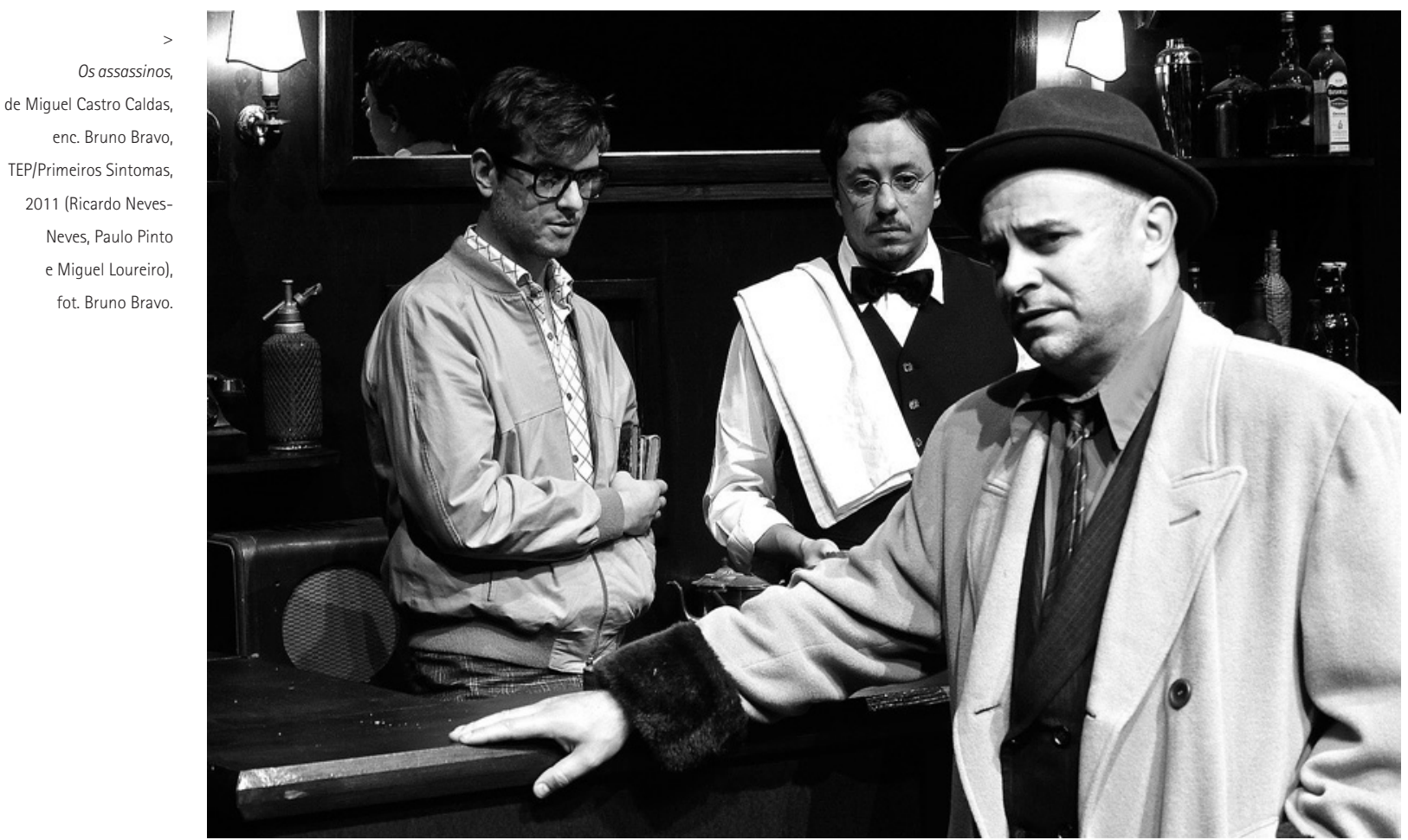

\title{
Uma maneira de dizer não
}

\section{Emília Costa}

Titulo: Os assassinos (2011). Autor: Miguel Castro Caldas, "ocupação" de um conto de Ernest Hemingway. Encenação: Bruno Bravo. Cenografia: Stéphane Alberto. Figurinos: Susana Sá. Desenho de luz: André Calado. Interpretação: Dinis Gomes, Miguel Loureiro, Paulo Pinto, Ricardo Neves-Neves, Susana Sá e António Mortágua. Co-produção: Círculo de Cultura Teatral - Teatro Experimental do Porto (TEP) e Primeiros Sintomas. Local e data de estreia: Auditório Municipal de Gaia, Vila Nova de Gaia, 05 de Maio de 2011 (Local do espectáculo em reposição:Teatro do Bairro Alto, Lisboa).

Mas há uma saída pra este mal-estar: Bertolt Brecht (1961: 314)

Os assassinos, conto de Ernest Hemingway, publicado em Março de 1927, foi por diversas vezes adaptado para o cinema, em filmes inesquecíveis, de que se destacam

Emília Costa é licenciada em Direito pela Faculdade de Direito da Universidade de Lisboa e mestranda em Estudos de Teatro na Faculdade de Letras da mesma Universidade. É autora das adaptações para teatro do livro

Timbuktu de Paul Auster, levado à cena no Teatro da Trindade em 2006; e do livro

0 jogador de Dostoievski, levado cena no São Luiz Teatro Municipal em 2011.
Assassinos de Robert Siodmak e Os assassinos de Andre Tarkovski, tendo sido recentemente reformulado por Miguel Castro Caldas, num texto teatral de refinada ironia.

Nesse conto, o Sueco, ao ser avisado que dois assassinos andam à sua procura para o matar, cansado de fugir, opta por não fugir. 0 conto acaba sem que se saiba o que aconteceu ao Sueco ou sequer as razões pelas quais o querem matar ou por que razão desistiu de fugir

No texto de Miguel Castro Caldas, a história de dois assassinos que entram num bar restaurante para matar o Sueco (tal como acontece no conto original) rapidamente se transforma numa reflexão sobre o poder do não, invocando-se outras referências literárias, como é o caso de Bartleby, o escriturário, de Herman Melville e de Um o empregado de escritório, prefere não fazer; no segundo caso, o artista da fome transforma o não comer em arte Em todas estas narrativas, o simples acto de dizer não (o artista da fome, de Franz Kafka. No primeiro caso, Bartleby, não fugir, o não fazer, o não comer) causa uma perturbação no normal decurso dos acontecimentos, uma profunda perplexidade pelo facto de os seus agentes agirem de maneira inesperada, não previsível. E a força demonstrada por estes profetas do não é inexorável, mesmo quando o destino é a morte. Qual é o poder de um assassino se a sua vítima não fugir? Qual é o poder do patrão se o trabalhador decidir não trabalhar? Qual é o poder da nossa necessidade de sobrevivência se um homem decidir não comer? E se um indivíduo ao dizer não causa um tão profundo abalo, o que poderia acontecer a uma sociedade se a grande maioria dos seus cidadãos decidisse, de um dia para o outro, não fazer, simplesmente não fazer?

Este é sem dúvida o grande desafio proposto pelo texto de Miguel Castro Caldas, brilhantemente encenado por Bruno Bravo, encenador principal do grupo de teatro Primeiros Sintomas, que co-produziu com o Teatro Experimental do Porto (TEP) o presente espectáculo, cuja estreia ocorreu em Maio de 2011 no Auditório Municipal de Vila Nova de Gaia, com posterior reposição, em Janeiro de 2012, no Teatro do Bairro Alto (sede do Teatro da Cornucópia), em Lisboa.

Numa perscrutante lucidez, Bruno Bravo deixou o texto respirar, dando espaço aos actores para pausadamente representarem os seus personagens, numa 


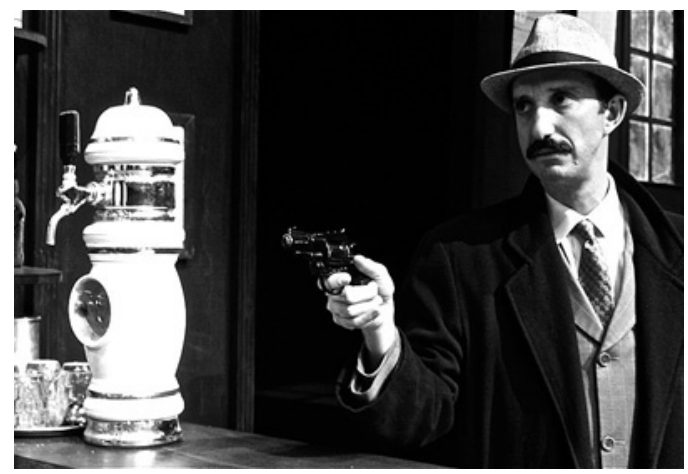

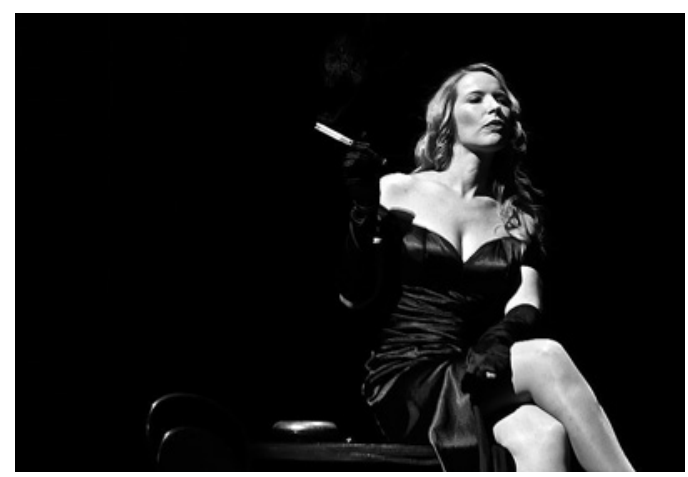

reflexão consigo próprios e com o público, que directamente confrontam nos olhos, quase convidando à participação. Optam mesmo, em determinados momentos, por prolongados silêncios, que, apesar de tantos incómodos provocarem nos actores e no público, neste caso, por genialmente conseguidos, apenas provocaram um grande momento de teatro.

Neste espectáculo, quer o actor/personagem quer o público têm tempo, tempo para ouvir, tempo para pensar, tempo para esperar. E é enquanto se espera pelo Sueco - que, de resto, nunca virá - que somos confrontados com a dificuldade que temos em abandonar os nossos papéis sociais, por mais absurdos que sejam. Nick, o jovem estudante, convincentemente representado por Ricardo Neves-Neves, ao se apoderar de uma das armas dos assassinos, provoca uma reviravolta na história: a vítima transmuda-se em carrasco. Mas Nick não quer ser nem o jovem estudante meio inconsciente meio amedrontado, nem o novo assassino deslumbrado pelo poder que a arma Ihe dá. Nick propõe uma alternativa ao óbvio. Afirma, tal como o fizeram o Sueco no conto de Hemingway, Bartleby no conto de Melville e o artista da fome no conto de Kafka, que as coisas podem ser diferentes. Que os assassinos podem abandonar o seu papel de assassinos, podem reescrever o texto. Mas nem Al, o assassino temperamental, na persuasiva versão do actor Miguel Loureiro, nem Max, o assassino frio, na inteligente versão do actor Dinis Gomes, aderem à provocação. Seja-se assassino ou empregado de escritório, a mudança aterroriza. É melhor manter-se o que se conhece, ainda que seja mau, do que apostar no desconhecido. A este trio junta-se ainda George, o barman, personagem central desta história, filósofo/leitor, cativantemente representado por Paulo Pinto, que invade, sem receios, as conversas dos dois assassinos, como se, apesar da postura agressiva e intimidatória destes, fosse ainda possivel dialogar, encontrar pontos de contacto independentemente da posição que cada um ocupa nas

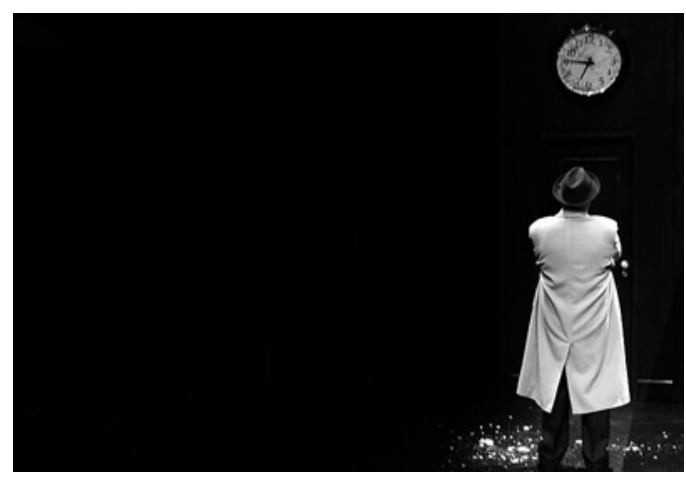

$\hat{\imath}$

Os assassinos,

de Miguel Castro Caldas, enc. Bruno Bravo, TEP/Primeiros Sintomas, 2011 ( $\wedge$ Dinis Gomes $<$ Susana Sá: $>$ Miguel Loureiro), fot. Bruno Bravo. inevitáveis e complexas relações de poder em que, em última análise, se traduzem sempre as relações humanas.

Num cenário realista, fielmente representativo de um bar americano na primeira metade do séc. XX (numa construção perfeita do cenógrafo Stéphane Alberto), com figurinos de uma sobriedade igualmente realista -, concertadamente concebidos por Susana Sá -, estabelecese, durante as duas primeiras partes do espectáculo, entre as quatro personagens nomeadas, um diálogo inteligente, cruel, irónico, absurdo, onde a história que se vive - a de dois assassinos que entram num bar para matar o Sueco - é também a história que se conta, como se apenas se representasse o que já está escrito, como se tudo sempre não passasse de fiç̧ão. É a história dentro da história, numa profunda homenagem ao poder encantatório da palavra, tão elucidativamente representada no momento em que Nick, ao contar a história do artista da fome, se apodera da pistola de Al, que, inebriado pela narrativa, não reage, tal como Schahriar não consegue matar Sherazade em As mil e uma noites.

A luz, num trabalho de André Calado, ilumina sobriamente o espaço, destacando o relógio, peça fundamental no cenário de uma história onde a espera determina a acção, e a zona do balcão, onde se encontra, na parede, pendurado, um espelho rectangular, com o qual as personagens contracenam, num jogo de verso e reverso, lembrando o enquadramento cinematográfico. 0 cinema é, aliás, uma das referências deste espectáculo, quer no texto que cita filmes, histórias de actores, de realizadores e de produtores, quer no próprio cenário e nas personagens que se inspiram assumidamente nos filmes de gangsters.

E de repente tudo muda. 0 diálogo acelera e abruptamente se interrompe num violento tiroteio, onde a escuridão total e a brancura dos clarões provocada pelos disparos se intercalam, numa típica cena americana de gangsters, mas aqui sem vencedores nem vencidos, sem 

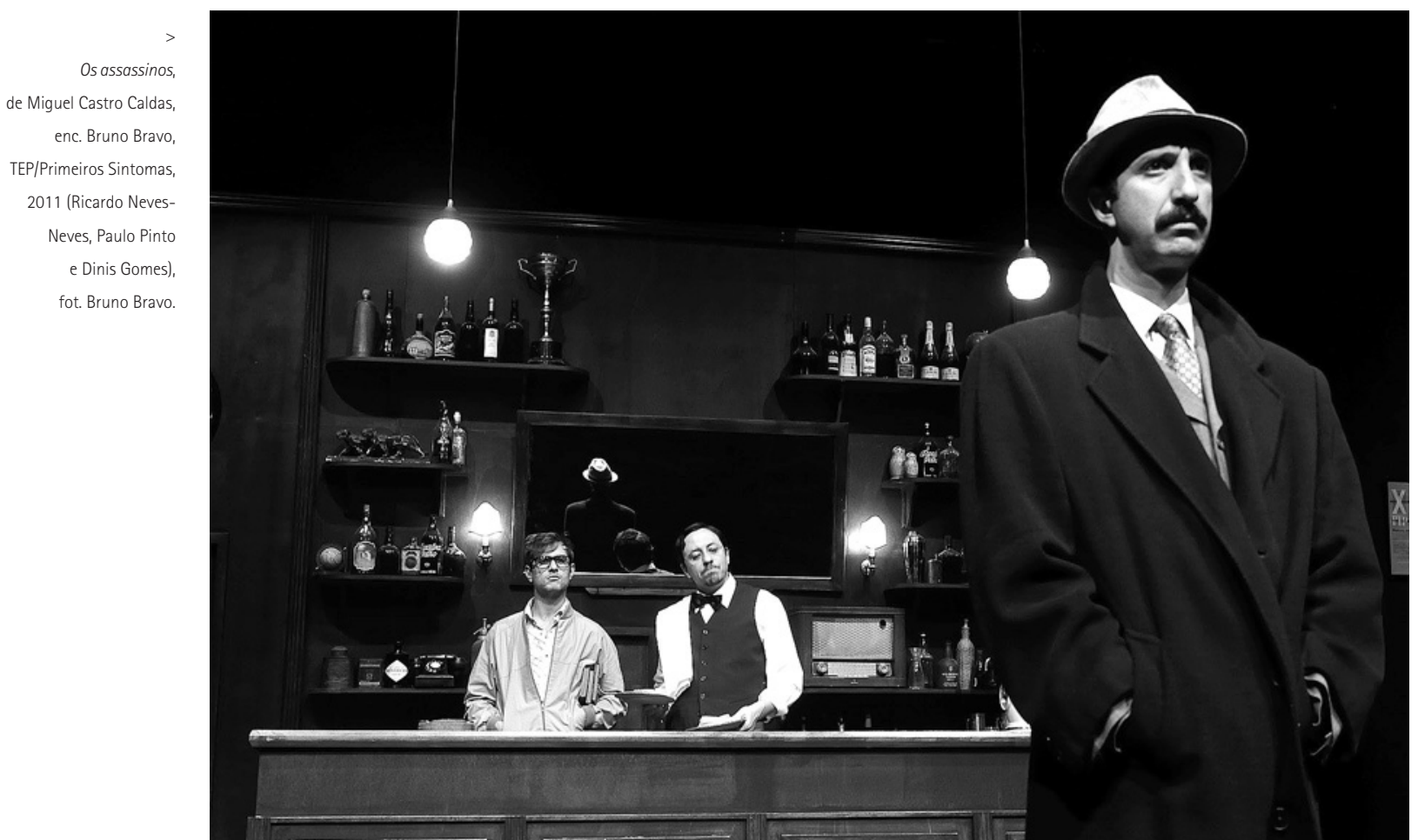

feridos nem mortos, para dar lugar à terceira e última parte deste desconcertante espectáculo.

Nesta última parte, surge-nos a Diva, talvez Ava Gardner, a actriz que Robert Siodmak, realizador do filme Assassinos, contratou para dar vida à mulher que foi obrigado a descobrir por detrás da história do Sueco, do homem que desistiu de fugir, como se em filme não fosse possivel um final em aberto. No filme, o conto de Hemingway é totalmente alterado: o Sueco é morto pelos assassinos e toda a misteriosa história do Sueco é revelada, numa invenção do argumentista Anthony Veiller, onde não podia deixar de existir uma bela mulher, razão de toda a trama.

A actriz Susana Sá, numa deslumbrante vedeta, vestida a rigor, com um belo e decotado vestido preto, luvas pretas até ao cotovelo, sapatos pretos de salto alto e obviamente bâton vermelho nos lábios, fuma por uma elegante boquilha. E é pela sua boca que, num monólogo abrilhantado de humor, ficamos a saber a história de Gente de domingo, filme primeiro de Robert Siodmak, ainda na Alemanha de 1929, antes da eleição democrática de Hitler, antes do extermínio de milhões de judeus, incluindo os pais de Robert Siodmak, antes da queda das duas bombas atómicas no Japão, quando a puerilidade, pelo menos aos domingos, ainda era possivel.

Também é através deste brilhante monólogo que apreendemos a incongruência das relações humanas, na amizade improvável entre Hemingway - homem de ideais de esquerda, defensor acérrimo dos republicanos, na guerra civil de Espanha de 1937 - e Gary Cooper, homem assumidamente de direita, que participou na perseguição dos comunistas no cinema americano, em que se destacou pela fúria persecutória o senador Joseph McCarthy. Não é fácil imaginar, como nos propõe sarcasticamente a Diva, o casal Hemingway e o casal Cooper de férias em inocentes diversões, enquanto tantos artistas, tantos amigos eram presos, ficavam sem emprego, apenas por suspeitas, levianamente investigadas, de simpatias comunistas.

É ainda a Diva que nos narra a história de um outro filme, 0 comboio apitou três vezes, este de cowboys, onde Gary Cooper, no papel do xerife Will Kane, perseguido por Frank Miller, também decide não fugir, ficar e enfrentar, sozinho, contra tudo e contra todos, e vencer como herói que é.

A mulher, a Diva - que não teve lugar no conto de Hemingway -, como todas as divas, divaga numa bebedeira solitária, apenas acompanhada por George, 0 barman, que protectoramente tenta que ela pare de beber e é ela, exactamente ela, que foi coagida a aparecer no filme comercial americano, quem, penetrantemente olhando para nós, espectadores, indaga se no escuro, no nosso sítio, existe alguém, pois parece-lhe ver alguém, parece ver-nos, num claro derrube da quarta parede, em plena sintonia com as teorias brechtianas. E é George, também olhando para nós, quem calmamente a sossega, afirmando que no nosso sítio apenas existe a casa de banho, enquanto os outros três personagens, sempre em palco, permanecem alheios à acção.

No momento histórico, em que vivemos, que propagandisticamente procura convencer-nos que não passamos de números, de meras peças substituiveis de uma realidade maior, a implacável economia, a que devemos cega obediência, numa evidente aproximação dos regimes ditatoriais, um espectáculo sobre a força, individual e colectiva, do não, é mais do que fundamental, é imprescindivel, e este espectáculo, na sua inteligente ironia, mostra-nos como a arte pode levar a pensar sem se descaracterizar.

\section{Referência bibliográfica}

BRECHT, Bertolt (1961), A boa alma de Sé-Chuão, trad. Ilse Losa, Lisboa, Portugália Editora. 